\title{
UTILITY OF AUTOFLUORESCENCE IMAGING IN THE DETECTION OF ORAL MUCOSAL LESIONS IN ELDERLY INSTITUTIONALISED SUBJECTS
}

Ramanathan A, Rosedee NA, Edwer SA, John EP, Palaniswany K, Bakar ZA. Utility of Autofluorescence Imaging in The Detection of Oral Mucosal Lesions in Elderly Institutionalised Subjects. Annal Dent Univ Malaya 2014; 21(1)

\begin{abstract}
The prevalence of oral mucosal lesions in elderly population is $22.8 \%$ to $61.6 \%$. Conventional oral examination (COE) is usually carried out to detect oral mucosal lesions (OML). However, new diagnostic aids have been introduced to improve OML detection. This study aimed to determine the utility of autofluorescence (AF) imaging in detecting OML from normal oral mucosa and its anatomic variation among institutionalised elderly Malaysian when compared with COE. Fifty subjects randomly selected from 9 nursing homes and COE and $\mathrm{AF}$ imaging using VELscope Vx, (LED Dental, Vancouver, British Columbia, Canada) were carried out. Sensitivity, specificity, positive (PPV) and negative predictive value (NPV) and accuracy of AF imaging were calculated. From the study, fifteen subjects had normal oral mucosa, 15 anatomic variations and 36 lesions were identified. The sensitivity and specificity of AF imaging were 100\% and $70 \%$ whereas the PPV and NPV were $80 \%$ and $100 \%$ respectively. The accuracy of AF imaging was $86.37 \%$ when compared to $\mathrm{COE}$. In conclusion AF imaging was able to detect OML and differentiate them from normal oral mucosa. However it has limited usefulness in differentiating between these lesions. This study however, was able to detail the AF imaging profile of normal oral mucosa, its normal variants and some common reactive or infective lesions which can be used in future OML studies as comparison to oral potentially malignant lesions.
\end{abstract}

Key words: Oral mucosal lesions; elderly institutionalised; conventional oral examination; autofluorescence imaging.

\section{INTRODUCTION}

Identification of oral mucosal lesions (OML) is important as it help in clinical diagnosis and treatment planning. Oral mucosal lesions are described as any abnormal changes on the mucous membrane lining of the oral cavity (1) such as red, white, mixed white and red, pigmented, ulcerative lesions and swelling. Examples of OML are given in Table 1 (2).

The prevalence of OML in elderly population has been reported as low as $22.8 \%$ to high as $61.6 \%$ (1) and the prevalence in Malaysia was reported as $22.8 \%$ (3). Various factors affect the prevalence of OML in this population and one major factor is the denture status (1).

Normal oral mucosa is pink in colour and consists histologically of two layers: the epithelium and the stroma (4). The epithelium is the stratified squamous
Original Article

Ramanathan $A^{1,2}$, Rosedee $N A^{1}$, Edwer $S A^{1}$, John $E P^{3}$, Palaniswany $K^{4}$, Bakar $Z A^{4}$.

${ }^{1}$ Department of Oro-Maxillofacial Surgical and Medical Science, Faculty of Dentistry, University of Malaya,

${ }^{2}$ Oral Cancer Research and Coordinating Centre, Faculty of Dentistry, University of Malaya, ${ }^{3}$ Department of Diagnostic and Integrated Dental Practice, Faculty of Science, University of Malaya, 50603 Kuala Lumpur, Malaysia.

${ }^{4}$ Primary Care Unit, Faculty of Dentistry, University

Malaysia 50728 Kuala Lumpur, Malaysia

Corresponding Author:

Dr. Anand Ramanathan

Email:drranand@um.edu.my

Table 1: Examples of different oral mucosal lesions

\begin{tabular}{|l|l|}
\hline Category & Example \\
\hline White lesion & $\begin{array}{l}\text { Pseudomembranous Candidiasis, } \\
\text { Homogenous leukoplakia, Lichen } \\
\text { planus etc. }\end{array}$ \\
\hline Red lesion & $\begin{array}{l}\text { Erythematous Candidiasis, } \\
\text { erytheroplakia, etc. }\end{array}$ \\
\hline $\begin{array}{l}\text { Mixed white and } \\
\text { red lesions }\end{array}$ & $\begin{array}{l}\text { Oral lichen planus, Non-homogenous } \\
\text { leukoplakia }\end{array}$ \\
\hline Pigmented lesion & Melanotic macule \\
\hline Ulcerated lesion & $\begin{array}{l}\text { Apthous ulcer, herpes ulcers, } \\
\text { neoplastic ulcers etc. }\end{array}$ \\
\hline Swelling & Mucocele, fibroepthilial polyp etc. \\
\hline
\end{tabular}

epithelium which consists of basal, intermediate and superficial squamous cells. The stroma is separated from the epithelium by the basement membrane. The stroma consists primarily of connective tissue containing mostly collagen. It also contains capillaries. The surface layer when keratinized contains keratin of varying thickness. Certain types of oral mucosa are naturally keratinized while others are not and can become keratinized as a result of chronic irritation or disease process (5). 
Diffuse reflectance contributes to how we perceive an object with our naked eye. Photons of light enter an object, get scattered and are reflected back to our eyes, if they do not get absorbed. White light is a mixture of all wavelengths of visible light such as blue, green, yellow and red. Short wavelength light like blue light, is absorbed very strongly by mucosal tissue. Not many blue photons are reflected back outside the tissue. Longer wavelength of the light like red, on the other hand is less absorbed by mucosal tissue and therefore red photons gets reflected from the tissue and reaches our eyes. Therefore the oral mucosal tissue is seen as predominantly red or pink in appearance.

Traditional methods of screening for oral mucosal lesions involve conventional oral examination (COE) with visual inspection of the oral cavity and palpation, usually performed by dentists or physicians. Visual inspection of the oral cavity is performed under normal (incandescent) light illumination, followed by palpation of suspicious lesions (6). However, $\mathrm{COE}$ is a poor discriminator of oral mucosal lesions (7). Therefore, to assist the clinician a number of optical aids have been developed espicially to differentiate benign lesions from sinister pathologies (7). One such optical aid is the autofluroscence (AF) imaging devices which have been used in the screening and diagnosis of precancers and early cancer of the lung, uterine cervix, skin and more recently, of the oral cavity (8).

One such AF imaging device is the Visually Enhanced Lesion scope (VELscope) which is a simple handheld device that allows direct visualization of alterations to tissue fluroscence (9). Blue excitation light ( 400 to $460 \mathrm{~nm}$ ) is produced by VELscope which tends to excite green fluorescence from endogenous flurophores in the oral mucosa (10).

Principal behind AF imaging is that the oral mucosa contains fluorophores, such as nicotinamide adenine dinucleotide dehydrogenase (NADPH), flavinadenine dinucleotide (FAD) and the cross-links between elastin and collagen. These fluorophores absorb blue photon and release lower energy, longer wavelength photons (green, red or yellow). These longer wavelength photons can be interpreted as fluorescence (10). However, diseased tissues have decreased number of NADPH, FAD and elastin and collagen cross-link hence fewer of the longer wavelength photons are released, and this lead to a decrease in the amount of fluorescence visualized $(6,11)$.

Many studies have reported the use of AF imaging in the identification of Oral potentially malignant disorders (OPMD), oral cancers $(8,9,12-14)$ and differentiating these lesions from other infective/inflammatory/benign lesions with varied results. However the characteristics of normal mucosa and non-OPMD/non-malignant (other lesions) under AF imaging have not been documented properly. Moreover the use of AF imaging has been limited to the clinical set-up (dental clinics and hospitals).
The main aim of the current study therefore was to determine the utility of autofluorescence imaging in detection of oral mucosal lesion from normal oral mucosa and its anatomic variation among elderly subjects in institutionalised setting in Malaysia when compared with conventional oral examination. In addition, it is the aim of this study to document the AF characteristics of normal oral mucosa and its anatomic variants and some common non-OPMD/non-malignant lesion. To our knowledge this is the first study to use AF imaging in the field, to identify OML in institutionalized elderly subjects.

\section{MATERIALS AND METHODS}

This study was part of the larger study, "Oral health and nutritional status, oral impacts, oral health knowledge and behaviour of elderly Malaysian in an institutionalized setting" and the Medical Ethical approval was obtained under the larger study. Fifty out of 160 elderly patients were randomly selected from 9 residential nursing homes around Klang Valley. Consent was obtained from all subjects under the broader program. The subject's information containing their general and sociodemographic details were extracted from the broader program.

\section{Extraoral and Intra-oral examination (Conventional oral examination-COE):}

Extraoral examination was carried out followed by a conventional intra-oral examination under white light by four qualified dentists (AR, ZAB, EPJ and KP) who had undergone training and calibration for identification and diagnosis of OML. The intra-oral examination was performed using a LED torch light, 2 mouth mirrors and few pieces of gauze. Intra-oral photographs of lesions were recorded using a digital camera (Cannon Power Shot A2200) provided with the AF imaging device.

\section{Autofluorescence examination:}

Intra-oral examination was followed by thorough investigation using AF imaging device (VELscope Vx, LED Dental, Vancouver, British Columbia, Canada) by the same dentist who performed the COE with white light in each patient. All four dentists had undergone training and calibration for examination with the AF imaging. Protective eyewear was provided to the patient. The possible outcomes of the AF examination were interpreted as either fluorescence visualization loss (FVL), fluorescence visualization retained (FVR) or fluorescence visualization increased (FVI). In areas where FVL was noticed, diascopic fluorescence (DF) was examined using a blunt end of the probe. The blunt end of the probe was run over the area of FVL and pressure applied (diascopy) and the presence or absence of blanching of the FVL area was 
noted. The outcomes of the AF examination were noted by the clinician. The recording of the COE diagnosis of the lesions and the outcome of the AF were performed by 2 trained assistants (SAE, NAR). Autofluorescence images (photographs) of the OML were recorded using the digital camera (Cannon Power Shot A2200) provided with the AF imaging device. The videos for the DF were also recorded.

\section{Statistical analysis:}

Sensitivity, specificity of $\mathrm{COE}$ and $\mathrm{AF}$ imaging and prevalence were calculated using diagnostic test calculator (14). Sensitivity and specificity were calculated as follows: Sensitivity $=\mathrm{TP} / \mathrm{TP}+\mathrm{FN}$

Specificity $=\mathrm{TN} / \mathrm{TN}+\mathrm{FP}$

True positive (TP) is a condition when the patient has the lesion and the test is positive (FVL or FVI) whereas, false positive (FP) is when the patient does not have the lesion but the test is positive. True negative (TN) is when the patient does not have the lesion and the test is negative and false negative (FN) is when the patient has the lesion but the test is negative. Positive Predictive Value (PPV) and Negative Predictive Value (NPV) were calculated as follows:

$\mathrm{PPV}=\mathrm{TP} / \mathrm{TP}+\mathrm{FP}$

$\mathrm{NPV}=\mathrm{TN} / \mathrm{TN}+\mathrm{FN}$

The accuracy of COE and AF imaging were calculated as follows:

Accuracy $=\mathrm{TP}+\mathrm{TN} /$ Positive + Negative

\section{RESULTS}

The sociodemographic characteristic of the study subjects $(\mathrm{n}=50)$ had a median age of 81 years with majority being females $(n=32 ; 72 \%)$ and Chinese $(n=47 ; 94 \%)$ the rest being Indians $(n=3 ; 6 \%)$. Only $6 \%(n=3)$ had smoked, $10 \%(n=5)$ had alcohol drinking habit and $4 \%(n=2)$ had betel quid chewing habit. About 52\% $(n=26)$ had either partial or complete dentures. Table 2 shows the clinical diagnosis by $\mathrm{COE}$ and the outcomes of $\mathrm{AF}$ examination in 50 subjects. Fifteen subjects had clinically normal oral mucosa whereas 13 anatomic variations and 38 lesions were identified in the rest. Fourteen patients had more than one lesion. They were grouped into 5 as follows: 1 . Normal, 2. Anatomic variation, 3. Inflammatory/ infective lesions, 4. Benign lesions and 5. Others.

All 15 subjects with clinically normal oral mucosa showed FVR under AF examination. Fifteen lesions diagnosed in the $2^{\text {nd }}$ group showed varying outcome on AF examination. All 3 cases of fordyce granule showed FVL $(100 \%)$, however 1 of the lesions also had FVI (33.33\%) and 2 lesions showed DF (66.67\%). Among 4 lingual varicosities, $66.67 \%$ (3) showed FVL with DF and $1(33.33 \%)$ showed FVR. All 3 lesions of leukoedema showed FVR (100\%). Out of the 3 fissured tongues, 1 $(33.33 \%)$ showed FVL and rest $(2 ; 66.67 \%)$ showed FVR. The pigmented lesions showed FVL but no DF.

The $3^{\text {rd }}$ group had 17 lesions out of which 15 showed FVL whereas the 2 cases diagnosed with candidiasis showed FVI. Among the 15 lesions with FVL, 1 angular chelitis showed both FVL and FVR under AF examination. All the 15 lesions with FVL also showed DF except one (abscess). The $4^{\text {th }}$ group had 13 lesions and all showed FVL with DF. The 6 lesions in the $5^{\text {th }}$ group showed varied AF outcome. The amalgam tattoo showed FVL but no DF whereas the haemorrhagic spot showed FVL with DF and FVI. All white coated tongue showed FVI, in addition 1 showed FVL without DF.

Lesions in group 3, 4 and 5 were considered to be with disease (lesion present) whereas group 1 and 2 were considered free of diseases (lesion absent). In AF examination, FVL and FVI were considered to be test positive whereas those with either FVR was considered test negative. Diascopic fluorescence were not considered in the analysis since DF was done only in cases of FVL and therefore all lesions with or without DF had FVL (test positive). Table 3 shows the TP, TN, FP and FN of AF imaging. The sensitivity and specificity of AF imaging were $100 \%$ and $70 \%$ whereas the PPV and NPV were $80 \%$ and $100 \%$. The accuracy of AF imaging was $86.37 \%$ when compared to COE (Table 3). 
Table 2: Clinical diagnosis and the outcome of autofluorescence examination in 50 subjects.

\begin{tabular}{|c|c|c|c|c|c|c|c|}
\hline Groups & Clinical diagnosis & $\begin{array}{c}\text { Number of } \\
\text { lesions }\end{array}$ & $\begin{array}{c}\text { FVL } \\
\text { n (\%) }\end{array}$ & $\begin{array}{l}\text { FVR } \\
\text { n (\%) }\end{array}$ & $\begin{array}{c}\text { FVI } \\
\text { n }(\%)\end{array}$ & $\begin{array}{c}\text { DIASCOPIC } \\
\text { n (\%) }\end{array}$ & AF test result \\
\hline Normal & Normal & 15 & $0(0.00)$ & $15(100.00)$ & $0(0.00)$ & $0(0.00)$ & Negative $=15$ \\
\hline \multirow{7}{*}{$\begin{array}{l}\text { Anatomical } \\
\text { variation }\end{array}$} & Fordyce granule & 3 & $3(100.00)$ & $0(0.00)$ & $1(33.33)$ & $2(66.67)$ & Positive $=3$ \\
\hline & \multirow[t]{2}{*}{ Lingual Varicosities } & \multirow[t]{2}{*}{4} & \multirow[t]{2}{*}{$3(66.67)$} & \multirow[t]{2}{*}{$1(33.33)$} & \multirow[t]{2}{*}{$0(0.00)$} & \multirow[t]{2}{*}{$3(100.00)$} & Positive $=3$ \\
\hline & & & & & & & Negative $=1$ \\
\hline & Leukoedema & 3 & $0(0.00)$ & $3(100.00)$ & $0(0.00)$ & $0(0.00)$ & Negative $=3$ \\
\hline & \multirow[t]{2}{*}{ Fissured tongue } & \multirow[t]{2}{*}{3} & \multirow[t]{2}{*}{$1(33.33)$} & \multirow[t]{2}{*}{$2(66.67)$} & \multirow[t]{2}{*}{$0(0.00)$} & \multirow[t]{2}{*}{$0(0.00)$} & Positive $=1$ \\
\hline & & & & & & & Negative $=2$ \\
\hline & Pigmentation & 2 & $2(100.00)$ & $0(0.00)$ & $0(0.00)$ & $0(0.00)$ & Positive $=2$ \\
\hline \multirow[t]{6}{*}{$\begin{array}{l}\text { Inflammatory/ } \\
\text { infective }\end{array}$} & $\begin{array}{c}\text { Denture induced } \\
\text { erythema/stomatitis }\end{array}$ & 6 & $6(100.00)$ & $0(0.00)$ & $0(0.00)$ & $6(100.00)$ & Positive $=6$ \\
\hline & Traumatic ulcer & 4 & $4(100.00)$ & $0(0.00)$ & $0(0.00)$ & $4(100.00)$ & Positive $=4$ \\
\hline & Abscess & 1 & $1(100.00)$ & $0(0.00)$ & $0(0.00)$ & $0(0.00)$ & Positive $=1$ \\
\hline & Angular cheilitis & 1 & $1(100.00)$ & $0(0.00)$ & $1(100.00)$ & $1(100.00)$ & Positive $=1$ \\
\hline & $\begin{array}{c}\text { Erythematous } \\
\text { candidiasis }\end{array}$ & 3 & $3(100.00)$ & $0(0.00)$ & $0(0.00)$ & $3(100.00)$ & Positive $=3$ \\
\hline & Candidiasis & 2 & $0(0.00)$ & $0(0.00)$ & $2(100.00)$ & $0(0.00)$ & Positive $=2$ \\
\hline \multirow[t]{5}{*}{ Benign lesion } & Mucocelle & 2 & $2(100.00)$ & $0(0.00)$ & $0(0.00)$ & $2(100.00)$ & Positive $=2$ \\
\hline & $\begin{array}{c}\text { Denture induced } \\
\text { hyperplasia }\end{array}$ & 2 & $2(100.00)$ & $0(0.00)$ & $0(0.00)$ & $2(100.00)$ & Positive $=2$ \\
\hline & Linea alba & 5 & $5(100.00)$ & $0(0.00)$ & $1(20.00)$ & $5(100.00)$ & Positive $=5$ \\
\hline & Frictional Keratosis & 3 & $2(66.67)$ & $0(0.00)$ & $1(33.33)$ & $2(66.67)$ & Positive $=3$ \\
\hline & Traumatic biting & 1 & $1(100.00)$ & $0(0.00)$ & $0(0.00)$ & $1(100.00)$ & Positive $=1$ \\
\hline \multirow[t]{3}{*}{ Others } & White coated tongue & 4 & $1(25.00)$ & $0(0.00)$ & $4(100.00)$ & $0(0.00)$ & Positive $=4$ \\
\hline & Hemorrhagic spot & 1 & $1(100.00)$ & $0(0.00)$ & $1(100.00)$ & $1(100.00)$ & Positive $=1$ \\
\hline & Amalgam tattoo & 1 & $1(100.00)$ & $0(0.00)$ & $0(0.00)$ & $0(0.00)$ & Positive $=1$ \\
\hline
\end{tabular}

Table 3: TP, TN, FP, FN, Sensitivity, Specificity, PPV, NPV and Accuracy of AF imaging.

\begin{tabular}{|l|c|c|c|c|}
\hline & $\begin{array}{c}\text { Inflammatory/infective/ } \\
\text { Benign lesion/ Others }\end{array}$ & $\begin{array}{c}\text { Normal/Anatomical } \\
\text { variation }\end{array}$ & Total & \\
\hline FVL/FVI & $36(\mathrm{TP})$ & $9(\mathrm{FP})$ & 45 & $\begin{array}{c}36 / 45=0.8 \\
\mathrm{PPV}=80 \%\end{array}$ \\
\hline FVR & $0(\mathrm{FN})$ & $21(\mathrm{TN})$ & 21 & $\begin{array}{c}21 / 21=1 \\
\mathrm{NPV}=100 \%\end{array}$ \\
\hline Total & 36 & 30 & 66 & $45 / 66=0.8636$ \\
& $36 / 36=1$ & $21 / 30=0.7$ & & \begin{tabular}{c} 
Accuracy $=86.37 \%$ \\
\hline
\end{tabular} \\
\hline
\end{tabular}

FVL - Fluorescent visualisation Loss, FVI - Fluorescent visualisation increased, FVR- Fluorescent visualisation retained, TP - True positive, FP - False positive, FN - False negative, TN - True negative, PPV - Positive predictive value and NPV - Negative predictive value

\section{DISCUSSION}

This study was a convenience sampling cross-sectional study in the elderly subjects in institutionalised setting in Malaysia to determine the utility of AF imaging in detecting OML. In the current study, 14 types of lesions, 5 anatomical variations and normal oral mucosa were recognized clinically and their AF findings were recorded in 50 elderly subjects and grouped into 5 .

Group 1:
Normal oral mucosa is said to retain fluorescence (i.e., FVR) and emit pale green autofluorescence (Figure 1 a \& b). Buccal mucosa predominantly appears green with AF imaging, however in few small areas of buccal mucosa, dark patches can be seen which are due to mild trauma or inflammation as buccal mucosa is a high risk site for trauma. The vermillion border and dorsum of the tongue show spectral difference compared to other normal mucosal lining with AF imaging (16). 
1 (a)

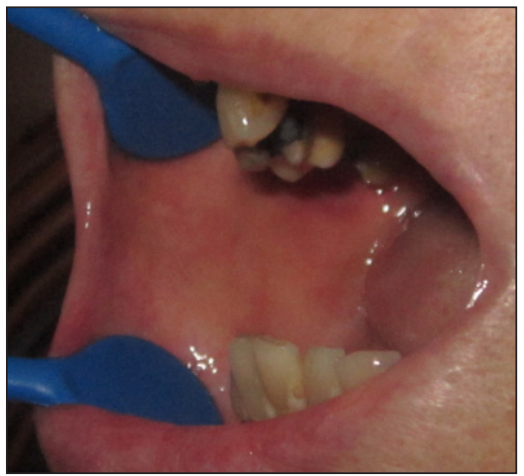

(b)

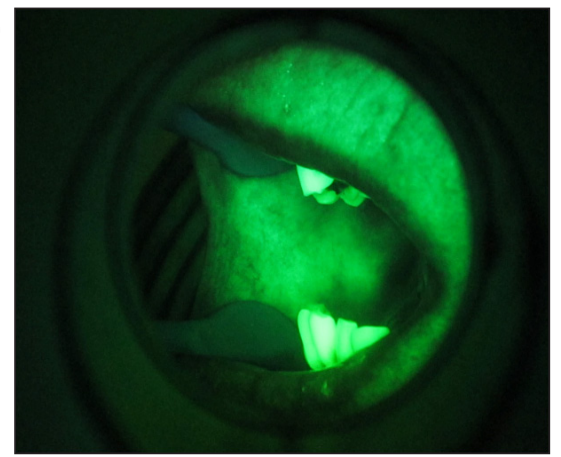

Figure 1: Photographs of right buccal mucosa (a) Norma mucosa on COE. (b)AF examination show green fluorescence (FVR) of the normal mucosa

\section{Group 2 (Anatomical variations):}

In this study, anatomical variations such as fordyce granules, lingual varicosities, leukoedema and fissured tongue were recognized clinically. Fordyce granules are small, elevated, yellowish areas on buccal mucosa (Figure $2 \mathrm{a}$ ). They are ectopic sebaceous gland and are not considered abnormal (17). They are small elevated variants on the buccal mucosa, a high risk site for trauma/irritation from the adjacent teeth causing localised inflammation leading to FVL with DF. Some areas of the buccal mucosa may have become keratinized due to chronic irritation thus explaining the FVI in one lesion (Figure $2 \mathrm{~b}$ ). Lingual varicosities are dilated tortuous veins in ventral surface of tongue (18) (Figure $2 \mathrm{c}$ ). The FVL in these variants may be explained by the increased blood supply in them resulting in increased absorption of light (Figure $2 \mathrm{~d}$ ). A filmy, white to slate grey and opaque discoloration of buccal mucosa are leukoedema (17). These variants partially disappeared when the mucosa is stretched and re-appear when unstretched. However AF examination showed normal green fluorescence of the buccal mucosa for these variants. Deep grooves or fissures in the midline of the dorsal surface of the tongue are fissured tongue (17) (Figure 2 e). On AF examination they appeared as normal green fluorescence with a slight dark colour in the groove (Figure $2 \mathrm{f}$ ). Dark black pigmentations on the oral mucosa (Figure $2 \mathrm{~g}$ ) contain melanin pigments which may cause increased light absorption therefore are seen as FVL without DF in AF imaging (Figure $2 \mathrm{~h}$ ).

\section{Group 3 (Inflammatory/infective lesions):}

Denture induced stomatitis (Figure 3a) refer to inflammation of the denture bearing mucosa and is a common problem in elders wearing complete or partial denture (19). Traumatic ulcers (Figure 3 c) are localized area of the oral mucosa with surface epithelium destroyed. They vary in shape and size, painful and present for short duration. They are common in older age group due to denture irritation (20). On AF imaging both these lesions showed FVL with DF (Figure $3 \mathrm{~b}$ and $3 \mathrm{~d}$ ). Inflammation in these lesions leads to increased blood flow to the affected area therefore resulting in FVL however on diascopy the blood is pushed away causing reappearance of fluorescence in the dark area which is termed as presence of DF.

Angular cheilitis is characterized as erythema, fissures and scales at the angle of the mouth due to reduced vertical dimension of occlusion leading to pooling of saliva favouring fungal growth (17). The FVL with DF in this lesion is due to inflammation whereas FVI may be due to the presence of scales or fungal hyphae. Presence of adherent white plaques with curdled milk appearance which can be scrapped-off is characteristic for acute pseudomembranous candidiasis (17) (Figure 3 e \& f). The FVI and some areas showing bright yellow fluorescence in these lesions may be due to the presence fungal hyphae. Erythematous candidiasis is characterized by multifocal red lesions and the FVL with DF observed in these lesions is due to inflammation.

\section{Group 4 (Benign lesions):}

Mucocele is a common OML, results from rupture of salivary gland duct causing spillage of mucin into the surrounding tissue. They are dome-shaped, bluish and fluctuant swellings, common in lower lip (17) (Figure $4 \mathrm{a}$ ). It is speculated that the FVL without DF observed (Figure $4 \mathrm{~b}$ ) on AF imaging may be due to the extravasated mucin which may absorb the blue light. Some areas of FVI were noted which may represent areas of hyperkeratosis. Denture induced hyperplasia is characterized by erythematous and papillary surface of the palatal mucosa of subjects wearing partial dentures (17) (Figure $4 \mathrm{c}$ ). The FVL with DF (Figure $4 \mathrm{~d}$ ) may be due to the associated inflammation.

Linea alba are white lines, usually present bilaterally on the buccal mucosa at the level of the occlusal plane of the adjacent teeth (17) (Figure 4 e). On AF imaging FVL with DF and sometimes with FVI (Figure $4 \mathrm{f}$ ) was observed which is due to inflammation and hyperkeratosis respectively. Moreover the diffuse borders of the inflamed region tend to fade away into the brighter green of the rest of the normal buccal mucosa.

Frictional keratosis is caused by chronic mechanical, frictional irritation of the oral mucosa and mostly associated with sharp tooth (Figure $4 \mathrm{~g}$ ) or a denture. On AF imaging (Figure 4 h) FVI was observed which may be explained by the presence of hyperkeratosis seen in these lesions. 
Group 5 (Other lesions):

White coated tongue (Figure $5 \mathrm{a}$ ) is a diffuse white coating on the dorsum of tongue which can be discoloured by food or drugs (17). The FVI observed in AF imaging (Figure $5 \mathrm{~b}$ ) may be due to presence of food debris on the surface of the tongue. Amalgam tattoo is characterized by a localized area of blue-grey macule (Figure $5 \mathrm{c}$ ) associated with the presence of a large amalgam restoration in the adjacent or opposing tooth (17). The amalgam incorporated into the oral mucosa may cause increased absorption of light and FVL without DF (Figure $5 \mathrm{~d}$ ) is observed in these lesions.

2 (a)

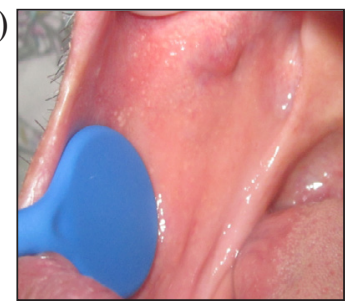

$2(\mathrm{e})$

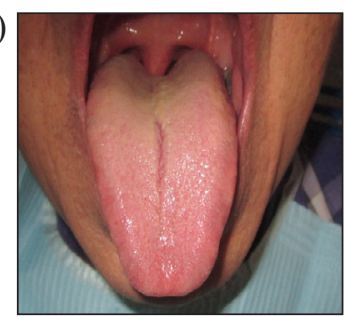

2 (b)

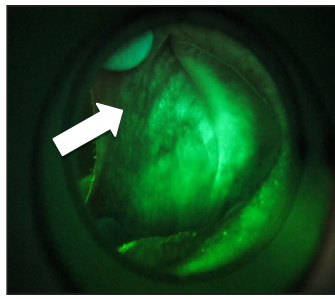

$2(\mathrm{f})$

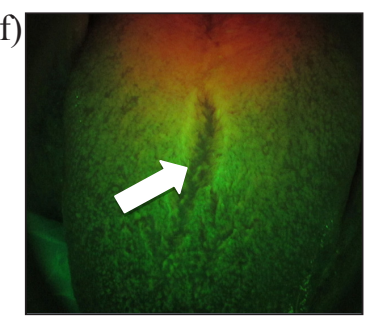

Table 4 gives the various findings of AF imaging for each lesion identified and diagnosed in this study. Many of the inflammatory/infective and benign lesions show similar findings with AF. Anatomical variants show varied AF findings. Therefore, AF imaging used alone may not be helpful in correct diagnosis of these lesions. This is supported by the claims of the company (LED Dental, Vancouver, British Columbia, Canada) that VELScope is intended to be used as an adjunct tool for clinical oral examination to improve the visualization of oral mucosal lesions.

Figure 2: Group 2 (Anatomical variants) Photographs (a) Fordyce granules on right buccal mucosa on COE. (b) AF examination show FVL of the fordyce granules (c) lingual varicosities on ventral surface of tongue by COE (d) AF examination show FVL of the lingual varicosities (e) Dorsum of the tongue showing deep groove by COE (f) AF examination show slight FVL in the deep groove on the dorsum of the tongue. (g) Black spots of pigmentation seen on the right buccal mucosa by COE (h) AF show FVL of the pigmented areas.

3 (a)

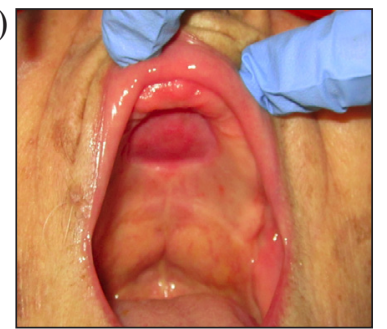

$3(d)$

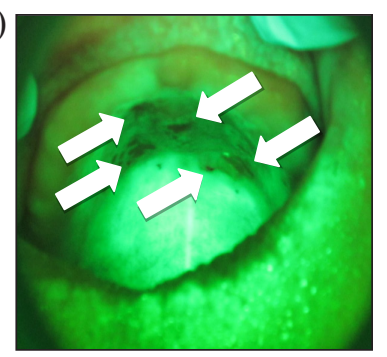

$3(\mathrm{~b})$

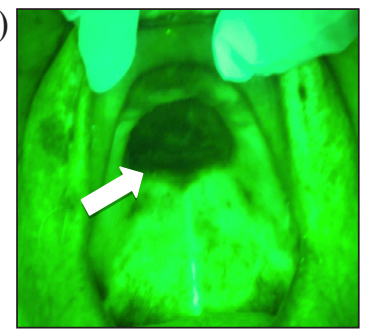

$3(\mathrm{e})$

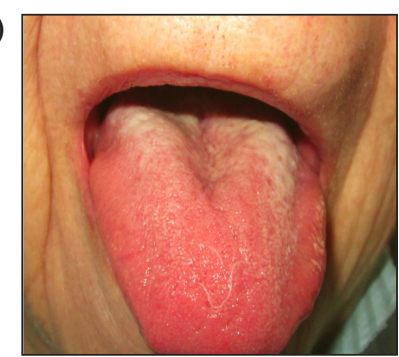

$3(\mathrm{c})$

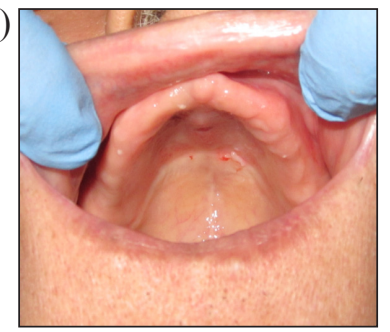

$2(\mathrm{f})$

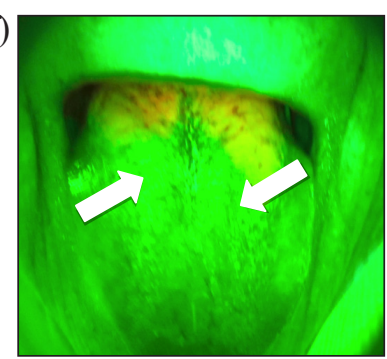

Figure 3: Group 3 (Inflammatory/Infective lesions) Photographs show (a) Denture induced stomatitis on denture bearing area on the palate by COE (b) AF shows FVL (white arrow) of the lesion of the palate (c) Traumatic ulcers on anterior hard palate by COE (d) AF show FVL (white arrows) of the lesions (e) Candidiasis on the dorsum of tongue by COE (f) AF show FVI (black arrows) of the lesion 
4 (a)

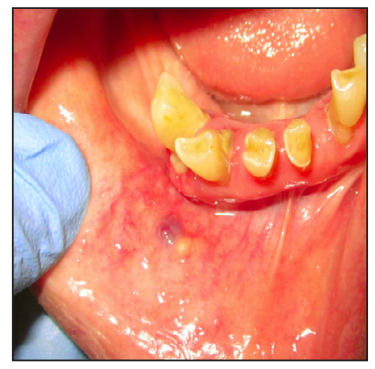

4 (d)

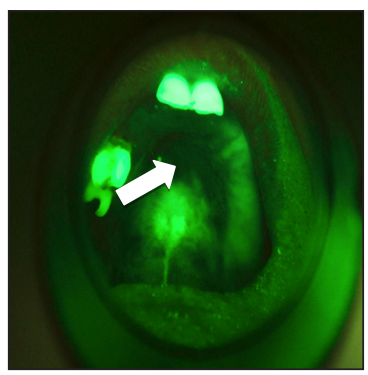

4 (b)

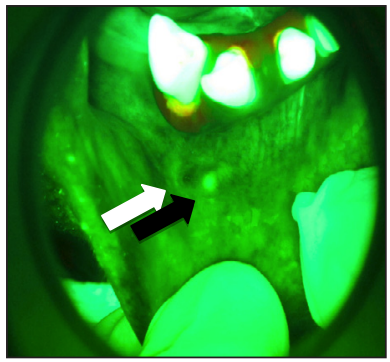

4 (e)

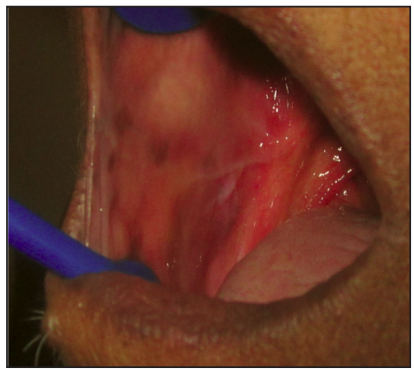

4 (c)

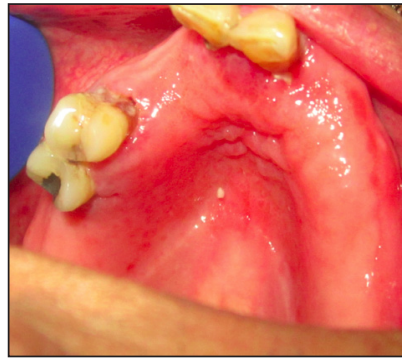

4 (f)

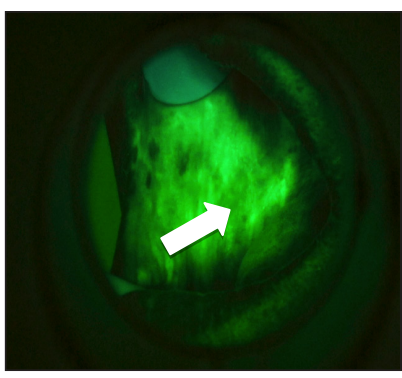

4 (g)

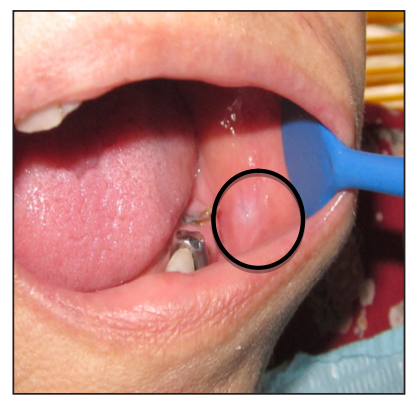

4 (h)

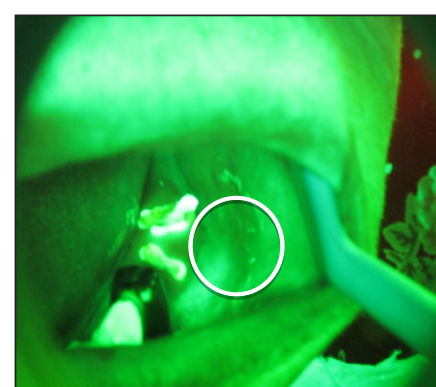

Figure 4: Group 4 (Benign lesions) Photographs show (a) Mucocele on lower labial mucosa by COE (b) AF show FVL (white arrow) with some areas of FVI (black arrow) (c) Denture induced hyperplasia on denture bearing area of the palate by COE (d) AF show FVL (white arrow) of the palate (e) Linea alba on right buccal mucosa by COE (f) AF show FVL (white arrow) (g) white area on left buccal mucosa adjacent to a sharp tooth (frictional keratosis) (black circle) (h) AF show at the area of lesion (white circle) on left buccal mucosa.

5 (a)

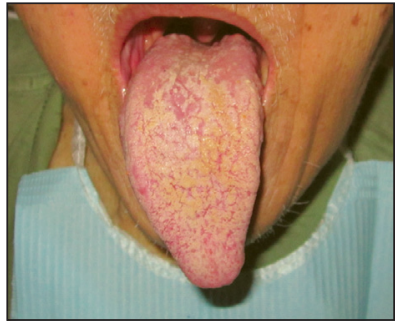

5 (c)

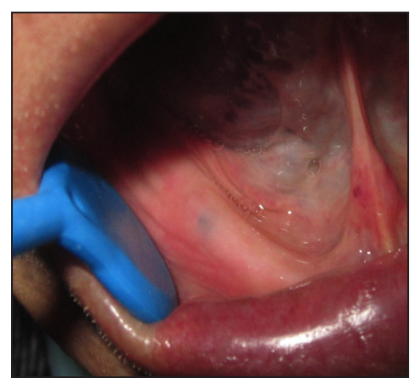

$5(b)$

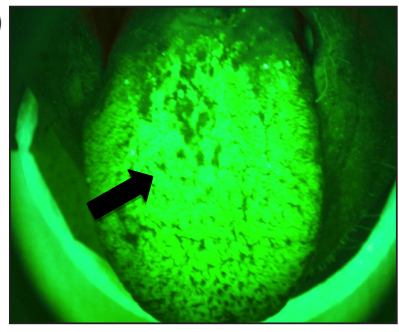

$5(d)$

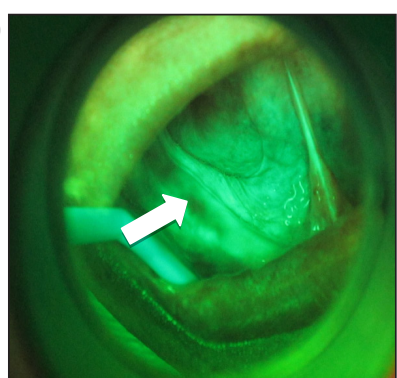

Figure 5: Group 5 (Others lesions) Photographs show (a) White coated tongue on the dorsal surface of tongue by COE b) AF show FVI (black arrow) on the dorsal surface of tongue (c) Amalgam tattoo on the right lower alveolar ridge (presence of a large amalgam restoration on the upper tooth is not shown) (d) AF show FVL (white arrow) noted at the right lower alveolar ridge. 
Table 4: Various findings of AF imaging for each lesion identified and diagnosed in this study

\begin{tabular}{|c|c|c|c|c|c|}
\hline \multirow{2}{*}{ GROUPS } & \multirow{2}{*}{ LESIONS } & \multicolumn{4}{|c|}{ AF FINDINGS } \\
\hline & & FVL & FVR & FVI & DF \\
\hline NORMAL & NORMAL & - & + & - & - \\
\hline \multirow{4}{*}{$\begin{array}{l}\text { ANATOMICAL } \\
\text { VARIATION }\end{array}$} & FORDYCE GRANULES & + & - & $-1+$ & $+/-$ \\
\hline & LINGUAL VARICOSITIES & $+/-$ & $-/+$ & - & $+/-$ \\
\hline & LEUKODEMA & - & + & - & - \\
\hline & FISSURED TONGUE & $-1++$ & $+/-$ & - & - \\
\hline \multirow{6}{*}{$\begin{array}{l}\text { INFLAMMATORY/ } \\
\text { INFECTIVE }\end{array}$} & DENTURE INDUCED ERYTHEMA/ STOMATITIS & + & - & - & + \\
\hline & TRAUMATIC ULCER & + & - & - & + \\
\hline & ABSCESS & + & - & - & - \\
\hline & ANGULAR CHEILITIS & + & - & + & + \\
\hline & ERYTHEMATOUS CANDIDIASIS & + & - & - & + \\
\hline & CANDIDIASIS & - & - & + & - \\
\hline \multirow{5}{*}{ BENIGN LESION } & MUCOCELE & + & - & - & + \\
\hline & DENTURE INDUCED HYPERPLASIA & + & - & - & + \\
\hline & LINEA ALBA & + & - & $-/+$ & + \\
\hline & FRICTIONAL KERATOSIS & $+/-$ & - & $-1+$ & $+/-$ \\
\hline & TRAUMATIC BITING & + & - & - & + \\
\hline \multirow{4}{*}{ OTHERS } & WHITE COATED TONGUE & $-1+$ & - & + & - \\
\hline & PIGMENTATION & + & - & - & - \\
\hline & HAEMARRHOGIC SPOT & + & - & + & + \\
\hline & AMALGAM TATTOO & + & - & - & - \\
\hline
\end{tabular}

Sensitivity of AF imaging was $100 \%$ since there was no FN detected by AF imaging when compared to COE however the specificity of $\mathrm{AF}$ imaging was $70 \%$ as anatomic variations were detected by $\mathrm{AF}$ imaging as loss of fluorescence. Therefore AF imaging was able to detect lesions if present effectively but on the other hand it was overestimating the presence of lesions. Therefore it is of importance that when using $\mathrm{AF}$ imaging, the examiner has thorough knowledge of anatomic variations of the oral mucosa, to avoid alarming the patient and subjecting them to unnecessary biopsies.

In other studies sensitivity of AF imaging has been reported from 30 to $100 \%$ but the specificity ranges from 15 to $81 \%(9,14,21,22)$. However these used AF imaging in detecting malignant and $\operatorname{OPMD}(8,12,13,25)$ and their subjects were either those with high risk or those already diagnosed with either OPMD or oral cancer. Therefore, these results cannot be compared to the present study since this study was designed to determine if $\mathrm{AF}$ imaging can detect lesions in general (inflammatory, infective, benign and others). Moreover the major limitation of this study was that histopathological analysis of tissue samples was not carried out since clinically sinister pathologies were not noted and most of the patients were old and refused biopsy. The PPV and NPV of AF imaging were $80 \%$ and
$100 \%$ therefore AF imaging was able to detect absence of lesions better than presence of lesions and the accuracy of $\mathrm{AF}$ imaging was $86.37 \%$ to $\mathrm{COE}$.

The use of AF imaging in general practice to detect OPMD and/or oral cancer is limited $(24,25)$. The use of $\mathrm{AF}$ imaging in general population institutionalized setting and in the field has not been carried out. Therefore, there is a need to do more work in this field to test the effectiveness of AF imaging in detecting OML in particular the OPMDs. With the characterisation of the AFs for normal mucosa and its anatomic variants as well as some common benign, reactive and inflammatory lesions in this study, future studies using AFs for OPMD when carried out, these findings which will be useful in discriminating between AFs of OPMDs and normal mucosa, anatomic variants and other lesions (non-OPMDs).

\section{CONCLUSION}

In conclusion AF imaging seems to be of use in detecting OML and differentiate them from normal oral mucosa and to some extent anatomic variants in this special study group of elderly subjects in institutionalised setting. However it has limited usefulness in differentiating between lesions 
as these lesions are already easily recognised by COE. Therefore, it is recommended that AF imaging, when used should be preceded by thorough COE under white light and should be carried out by experienced and trained dentist (in both $\mathrm{COE}$ and $\mathrm{AF}$ imaging) having sound knowledge about the anatomical variation of normal oral mucosa and oral mucosal lesions.

\section{ACKNOWLEDGEMENT}

The authors would like to acknowledge all subjects who gave their times and effort to be involved in this research. Thanks to the directors and staffs of each residential nursing homes. The authors would like to thank all members involved in the bigger project titled "Oral health and nutritional status, oral impacts, oral health knowledge and behaviour of elderly Malaysian in an institutionalized setting" and especially Dr. Jacob John Chiremel Chandy. The authors would like to thank Prof. Dr. Warnakulasuriya K.A.A.S and Prof. Dr. Noorlide Abu Kasim for their help in the analysis. The authors would like to acknowledge Ms. Siti Noriefah Sabari of Oral Cancer Research and Coordinating Centre (OCRCC) for her help. This research is supported by High Impact Research MoE Grant UM.C/625/HIR/MoE/DENT/24 from the Ministry of Education Malaysia.

\section{REFERENCES}

1. Espinoza I, Rojas R, Aranda W, Gamonal J. Prevalence of oral mucosal lesions in elderly people in Santiago, Chile. J Oral Pathol Med. 2003; 32(10): 571-75.

2. Neville B, Damm DD, Allen CM, Bouquot J. Oral and Maxillofacial Pathology. $3^{\text {rd }}$ Edition. (2008). Saunders, Philadelphia, Pennsylvania.

3. Taiyeb Ali TB, Razak IA, Latifah RJ, Zain RB. An epidemiological survey of oral mucosal lesions among elderly Malaysians. Gerodontol. 1995; 12(1): 37-40.

4. Dawson DV, Drake DR, Hill JR, Brodgen KA, Fischer CL, Wertz PW. Organization barrier function and antimicrobial lipids of the oral mucosa. Int $\mathrm{J}$ Cosmetic Sci. 2013; 35: 220-23.

5. Coulthard P, Horner K, Sloan P and Theaker E. Oral and Maxillofacial Surgery, Radiology, Pathology and Oral Medicine. Master Dentistry Volume I. $3^{\text {rd }}$ Edition. (2013). Churchill Livingstone, Edinburgh.

6. Shin D, Vigneswaran N, Gillenwater A, RichardKortum R. Advances in fluorescence imaging techniques to detect oral cancer and its precursors. Future Oncol. 2010; 6:1143-54.
7. Bhatia N, Lalla Y, Vu AN, Farah CS. Advances in optical adjunctive aids for visualization and detection of oral malignant and potentially malignant lesions. Int J Dent. 2013; 1-17.

8. De Veld DC, Wites MJ, Sterenborg HJ, Roodenburg JL. The status of in vivo autofluorescence spectroscopy and imaging for oral oncology. Oral Oncol. 2005, 41: 117-31.

9. Farah CS, Mclntosh L, Georgious A, McCullough MJ. "Efficacy of tissue autofluorescence imaging (VELscope) in the visualization of oral mucosal lesions." Head and Neck. 2011; 34: 856-62.

10. Farah CS and McCullough MJ. Oral cancer awareness for the general practitioner: new approaches to patient care. Aust Dent J. 2008; 53: 2-10.

11. Roblyer D, Kurachi C, Stepanek V, Williams MD, El-Naggar AK, Lee JJ, Gillenwater AM, RichardsKortum R. Objective detection and delineation of oral neoplasia using autofluorescence imaging. Cancer Prev Res (Phila). 2009; 2: 423-31.

12. Gillenwater A, Jacob R, Ganeshappa R, Kemp B, ElNaaggar AK, Palmer JL, Claymon G, Mitchell MF, Richards-Kortum R. Noninvasive diagnosis of oral neoplsia based on fluorescence spectroscopy and native tissue autofluorescence. Arch Otolaryngol Head Neck Surg. 1998; 124: 1251-1258.

13. Poh CF, Zhang L, Anderson DW, Durham JS, Williams PM, Priddy RW. Fluorescence visualization detection of field alterations in tumour margins of oral cancer patients. Clin Cancer Res. 2006; 12: 6716-22.

14. Awan KH, Morgan PR, Warnakulasuriya S. Evaluation of an autofluorescence based imaging system (VELscope ${ }^{\mathrm{TM}}$ ) in the detection of oral potentially malignant disorders and benign keratoses. Oral Oncol. 2011; 47: 274-277.

15. Lalkhen AG and McCluskey A. Clinical tests: sensitivity and specificity. Continuing Education in Anaesthesia, Critical Care \& Pain. 2008; 8(6): 2213.

16. De Veld DC, Skurichina M, Witjes MJ, Duin RP, Sterenborg WM, Star WM, Rooderburg JL. Autofluorescence characteristics of healthy oral mucosa at different anatomical sites. Lasers Surg Med. 2003; 32: 367-76.

17. Neville BW, Damm DD, Allen CM, Bouquot JE. Oral and Maxillofacial Pathology. $2^{\text {nd }}$ edition. (2004). Saunders, Philadelphia, Pennsylvania.

18. Cawson RA and Odell EW. Oral Pathology and Oral Medicine. $8^{\text {th }}$ edition. (2008). Churchill Livingstone Elsevier.

19. Pattanaik S, Vikas BVJ, Pattanaik B, Sahu S, Lodam S. Denture Stomatitis: A literature review. Jaypee Journals. 2010; 22(3): 136-40. 
20. Dunlap CL and Barker BF. A Guide to Common Oral Lesions. Department of Oral and Maxillofacial Pathology UMKC School of Dentistry.

21. Rana M, Zapf A, Kuehle M, Gellrich NC, Eckardt AM. "Clinical evaluation of an autofluorescence diagnostic device for oral cancer detection: a prospective randomized diagnostic study." European J Cancer Prev. 2012; 21, 460- 6.

22. Scheer M, Neugebauer J, Derman A, Fuss J, Drebber U, Zoeller JE. "Autofluorescence imaging of potentially malignant mucosa lesions," Oral Surgery Oral Med Oral Pathol. 2011; 111: 568-77.

23. Huff K, Stark PC, Solomon LW. "Sensitivity of direct tissue fluorescence visualization in screening for oral premalignant lesions in general practice," Gen Dent. 2009; 57(1): 34-8.

24. Truelove EL, Dean D, Maltby S, Griffith M, Huggins K, Griffith M, Taylor S. "Narrow band (light) imaging of oral mucosa in routine dental patients. Part I: assessment of value in detection of mucosal changes," Gen Dent. 2011; 59(4): 281-90.

25. McNamara KK, Martin BD, Evans EW, Kalmar JR. "The role of direct visual fluorescent examination (VELscope) in routine screening for potentially malignant oral mucosal lesions," Oral Surgery Oral Med Oral Pathol. 2012; 114: 636-43. 